\title{
Preface: Earth Observation for Integrated Water and Basin Management: Challenges for adaptation to a changing environment
}

\author{
María J. Polo ${ }^{1}$, Maria P. González-Dugo ${ }^{2}$, and Christopher Neale ${ }^{3}$ \\ ${ }^{1}$ Andalusian Institute for Earth System Research, University of Cordoba, Córdoba, Spain \\ ${ }^{2}$ Andalusian Institute of Agricultural and Fisheries Research and Training (IFAPA), Córdoba, Spain \\ ${ }^{3}$ Robert B. Daugherty Water for Food Global Institute, University of Nebraska, Lincoln, USA
}

Correspondence: María J. Polo (mjpolo@uco.es)

Published: 18 December 2018

Integrated river basin management involves a sound knowledge of water and land interactions, and impacts from and feedbacks to human activity. Remote sensing has been an efficient and increasingly promising means of gathering direct information of the Earth surface, as well as information on water and energy fluxes. The recent generation of high-resolution sensors offers a huge potential for monitoring, assessing, and modelling our changing environment in a context of uncertainty about how future climate conditions will affect the current water resource and basin management framework. Moreover, large amounts of data are now available posing a challenging opportunity to the scientific community for both exploring and transforming these data into readily usable information products for different end-users in our societies.

The scientific decade 2013-2022 of IAHS, entitled "Panta Rhei - Everything Flows", is dedicated to research activities on change in hydrology and society. Undoubtedly, remote sensing from different sources provides us with the information needed to monitor the environment at different spatial and temporal scales. Renewed efforts are needed to merge different data sources for generating medium to long-term series that benefit from both earlier satellite missions and the recent availability of high quality data provided by the new satellites and airborne technologies.

The Remote Sensing and Hydrology Symposium (RSHS) is organized every four years by the International Commission of Remote Sensing (ICRS) of the International Association of Hydrological Sciences (IAHS). This conference is a meeting point for researchers from both the hydrology and remote sensing communities, and brings together their joint experience in Earth Observation for developing innovative and environmentally-sustainable water resources and basin management. The 4th edition, RSHS'18, was hosted by the Andalusian Institute for Earth System Research at the University of Cordoba, Spain, during 8-10 May 2018, who provided the venue facilities and sponsored the conference, with support from the IFAPA in Cordoba, and the Daugherty Water for Food Global Institute at the University of Nebraska.

RSHS' 18 focused on the use of the new generation of remote sensors and applications to hydrology, water resources, agricultural water management and river basin management, and the challenges of blending remote sensing images and data sources with multi-scale modelling and ground-based data. Under the light of these objectives, innovative and integrated remote sensing research and applications were presented and discussed within the different thematic areas of the Symposium:

- Current and future missions for water cycle observation

- Observations of water cycle components

- Earth Observation retrievals and data products linked to the water cycle

- Applications of remote sensing data in water resources management

- Crop irrigation management by remote sensing

- Water quality and soil cover assessment from remote sensing data

This volumen gathers a selection of the works presented in RSHS'18. The Organizing Committee thanks all the people 
who made the conference a successful research discussion forum. IAHS provided sound institutional support and framework for the conference development. Three brilliant keynote lectures brought cutting-edge research on hydrological applications of remotely sensed data from different domains in the spectrum, and motivated questions for the discussion sessions:

- William Kustas, USDA-ARS, USA

The Grape Remote sensing Atmospheric Profile and Evapotranspiration eXperiment (GRAPEX)-A sinopsis

- José Moreno, University of Valencia, Spain

Vegetation fluorescence as a tool to monitor plant stress conditions: The FLEX Earth Explorer mission

- Claudia Notarnicola, EURAC, Italy

Addressing hydrological challenges by exploiting remotely sensed imagery in the microwave domain

The work carried out by Elisabet Carpintero, Pedro GómezGiráldez, Elena Herrera, and María-José Pérez-Palazón in the Local Committee to produce an enjoyable time during the technical sessions and the social events is also acknowledged.

The work of the Scientific Committee is especially acknowledged, who revised the 127 abstracts submitted to the Symposium, and finally accepted 40 as posters and 87 as oral presentations:

- Martha Anderson, USDA-ARS Hydrology \& Remote Sensing Lab

- Ana Andreu, University of Berkeley

- Gilles Boullet, IRD-CESBIO

- Alfonso Calera, University of Castilla-La Mancha

- Yangbo Chen, Sun Yat-sen University
- Michael Cosh, USDA-ARS Hydrology \& Remote Sensing Lab

- Guido d'Urso, Universita' degli Studi di Napoli Federico II

- Simon Gascoin, CNRS-CESBIO

- Maria P. González-Dugo, IFAPA-Junta de Andalucía

- Christopher Hopkinson, University of Lethbridge

- William Kustas, USDA-ARS Hydrology \& Remote Sensing Lab

- José Martínez Fernández, University of Salamanca

- Pamela Nagler, U.S. Geological Survey

- Christopher Neale, University of Nebraska

- Claudia Notarnicola, EURAC

- Rafael Pimentel, Swedish Meteorology and Hydrology Institute

- Maria J. Polo, University of Cordoba

- Andreas Schumann, University of Bochum

- Bob Su, University of Twente

- Julie Zinnert, Virginia Commonwealth University

56 works out from the oral presentations were selected by the Scientific Committee as full papers for the PIAHS volume of the conference. The Editors would like to thank Mario Ebel and Sarah Schneemann at Copernicus for their work and valuable support during the abstract submission process and the production of this volume. 